\title{
Future impacts of environmental factors on achieving the SDG target on child mortality—A synergistic assessment
}

\author{
Paul L. Lucas ${ }^{\mathrm{a}, *}$, Henk B.M. Hilderink ${ }^{\mathrm{b}}$, Peter H.M. Janssen ${ }^{\mathrm{a}}$, Samir KC ${ }^{\mathrm{c}, \mathrm{d}}$, \\ Detlef P. van Vuuren ${ }^{\mathrm{a}, \mathrm{f}, 1}$, Louis Niessen ${ }^{\mathrm{e}, \mathrm{g}, 1}$ \\ ${ }^{\text {a }}$ PBL Netherlands Environmental Assessment Agency, PO Box 30314, 2500 GH The Hague, the Netherlands \\ ${ }^{\mathrm{b}}$ National Institute for Public Health and the Environment (RIVM), PO Box 1, 3720 BA Bilthoven, the Netherlands \\ ${ }^{\mathrm{c}}$ Asian Demographic Research Institute, Shanghai University, 99 Shangda Road, Shanghai, China \\ ${ }^{\mathrm{d}}$ Wittgenstein Centre for Demography and Global Human Capital, IIASA, Schlossplatz 1, A-2361 Laxenburg, Austria \\ ${ }^{\mathrm{e}}$ Health Economics Unit, Liverpool School of Tropical Medicine, Pembroke Place, Liverpool L38PQ, United Kingdom \\ ${ }^{\mathrm{f}}$ Copernicus Institute for Sustainable Development, Department of Geosciences, Utrecht University, Heidelberglaan 2, 3584 CS Utrecht, the Netherlands \\ ${ }^{\mathrm{g}}$ Department of International Health, Johns Hopkins School of Public Health, NW Wolfe Street, Baltimore, MD 21205, United States
}

\section{A R T I C L E I N F O}

\section{Keywords:}

Sustainable development goals

Child mortality

Integrated analysis

Environmental risk

\begin{abstract}
A B S T R A C T
An estimated $26 \%$ of current global child deaths can be attributed to various and modifiable environmental factors, which are addressed under multiple Sustainable Development Goals (SDGs). This study assesses future reductions in child mortality in relation to the achievement of environment-related SDG targets. It uses projections of health risk factors from the IMAGE 3.0 Integrated Assessment Model, based on the Shared Socioeconomic Pathways (SSPs), linked to a standard multi-state health model (GISMO), distinguishing risk factors, disease occurrence and cause-specific death. The study concludes that, on a global level, the SDG target on child mortality will not be achieved in any of the three SSP scenarios analysed, mainly due to persistent high mortality rates in Sub-Saharan Africa and South Asia. By 2030, environmental health risk factors - including childhood undernutrition, no access to improved drinking water and sanitation, no access to modern fuels and exposure to malaria - will still be responsible for $14 \%$ to $16 \%$ of total global child deaths ( $8 \%$ to $10 \%$ when excluding nutrition-related mortality). Under the middle-of-the-road SSP2 baseline scenario, achievement of the SDG targets on hunger, drinking water and sanitation and modern energy services, would avoid 433 thousand child deaths by 2030 . If, in addition, also higher standards would be achieved for access to water and energy, as well as universal secondary female education and advanced malaria control, a total of 733 thousand child deaths is projected to be avoided by 2030 (444 thousand child deaths, when excluding nutrition-related mortality), which would reduce projected global child mortality by $13 \%$. Overall, more than $25 \%$ of the child mortality reduction that is needed to achieve the SDG target in Sub-Saharan Africa can be achieved through SDG-related policies on food, water and energy. This requires integrated and intersectoral approaches to environmental health.
\end{abstract}

\section{Introduction}

Child mortality is an important indicator of human development, with high levels of child mortality generally being associated with low development levels and vice versa. This is also recognised in the 2030 Agenda for Sustainable Development and its 17 Sustainable Development Goals (SDGs) (UN, 2015). The SDGs not only address the eradication of extreme poverty and its symptoms (including health impacts), but also, among many other areas, the underlying dynamics of human, environmental and economic developments. The SDGs thus reframe health from the more narrow poverty reduction focus of the Millennium Development Goals to being an integral part of sustainable development (Hill et al., 2014; WHO, 2016). SDG 3 is about health and well-being for all, and target 3.2 is to, by 2030 , end preventable deaths of children under 5 years of age, with all countries aiming to reduce under- 5 mortality to at least as low as 25 deaths per 1000 live births. In 2015 , about 75 countries had higher child mortality rates, partly due to the persistent and sometimes even increasing environmental risks in

\footnotetext{
* Corresponding author.

E-mail address: paul.lucas@pbl.nl (P.L. Lucas).

${ }^{1}$ Equally contributed.
} 
low- and middle-income countries (Lim et al., 2016).

An estimated $26 \%$ of the total number of child deaths, globally, can be attributed to environmental factors, contributing to the occurrence of infectious and parasitic diseases, neonatal and nutritional conditions and physical injuries (Prüss-Ustün et al., 2016). Major infectious diseases include pneumonia, diarrhoea and malaria (WHO, 2017b), which, in 2015 , were responsible for a respective $16 \%, 9 \%$ and $5 \%$ of global child mortality (Liu et al., 2016). Furthermore, in 2011, child underweight was related to about $15 \%$ of the total number of child deaths (Black et al., 2013). Pneumonia is associated with exposure to carbon monoxide and fine particle emissions, caused by the use of traditional biomass on open fires or traditional stoves (Dherani et al., 2008). Diarrhoea is strongly associated with exposure to micro-pathogens, caused by unsafe drinking water sources and sanitation and lack of hygiene (Wolf et al., 2014). Malaria is closely related to environmental factors, as the mosquitoes spreading the infection can only survive under specific climatic conditions, with high average temperatures, no frost and high levels of humidity and precipitation. Furthermore, climate change may cause the areas suitable for malaria mosquitoes to expand (Martens et al., 1995). Finally, underweight contributes to child mortality via nutritional diseases, and is an underlying risk factor for pneumonia, diarrhoea and malaria, increasing both disease incidence and mortality. Therefore, achieving SDG targets on hunger (SDG 2), malaria incidence (SDG 3), drinking water and sanitation (SDG 6), modern sources of energy (SDG 7) and climate change (SDG 13) is also important for the achievement of the SDG on child mortality (WHO, 2017a). This integrated nature of the SDGs calls for systematic analysis of the many trade-offs and synergies between the broad range of goals and targets (Le Blanc, 2015; Nilsson et al., 2016; Niessen et al., 2018).

The use of integrated models to project long-term developments in human health helps to understand the links between health and other markers of human progress, and provides insight into key leverage points for future improvements (Hughes et al., 2011). For example, integrated modelling has been used to estimate the avoidable burden of disease that is related to specific risk factors (Kuhn et al., 2016), and the cost-effectiveness of various types of health interventions (Niessen et al., 2009; Van Ekdom et al., 2011). Various studies have projected child mortality for 2030. Liu et al. (2015) and You et al. (2015) applied trend extrapolations, assuming that trends in cause-specific mortality between 2000 and 2013 would continue until 2030. Mathers and Loncar (2006) applied a regression model of sex- and age-specific mortality with indirect, or distal, determinants of health, for 10 clusters of major causes. However, these three studies do not take changes in the underlying health risk factors into account, nor do they allow for a synergistic analysis. Only a few studies do. Hughes et al. (2011) expanded on projections by Mathers and Loncar (2006) by integrating their baseline estimates and formulations into the International Futures (IFs) integrated modelling framework and incorporating proximate health drivers and structural representations of some important health issues. The model allows for assessment of the potential benefits of health policy intervention for socio-economic development. Hilderink et al. (2008) developed a multi-state health model (GISMO) that links socio-economic and environmental risk factors to disease incidence and death. Linking the model to the IMAGE3.0 integrated assessment modelling framework (Stehfest et al., 2014) allows for assessment of the role of environmental risk factors in long-term developments in human health (Hilderink et al., 2009; Van Vuuren et al., 2015).

For our study, we used the GISMO model, together with IMAGE3.0, to assess the role of environmental factors in future developments in child mortality. The analysis goes further than most other studies, by specifically addressing cross-sectoral relationships between various SDGs. The following research questions are addressed:

- Is the world on track to achieve the SDG target on child mortality?

- What is the role of environmental factors in future developments in global child mortality?
- What is the impact of achieving environment-related SDG targets on achieving the SDG target on child mortality?

We project future developments in child mortality and attributable death in relation to a range of environmental health risk factors, including food availability, access to improved drinking water and sanitation, access to modern sources of energy, and climate change. The projections build on the IMAGE implementation of the Shared Socioeconomic Pathways (SSPs), which are a set of five storylines about possible trajectories for human development and global environmental change, during the 21 st century (Riahi et al., 2017; Van Vuuren et al., 2017a). Thereby, the study responds to the call for specific incorporation of human health indicators in the SSPs (see Ebi, 2014; Van Ruijven et al., 2014).

\section{Methods}

We used a tested and widely published long-term integrated assessment model (IMAGE) linked to a population health model (GISMO) to assess future developments and child mortality attributable to a selection of environmental health risk factors. The integrated assessment model provides a structural representation of such risk factors. The population health model describes the causal relationships between these risk factors and child mortality, using relative risk ratios from the literature. Three distinct scenario storylines, which describe future developments in key aspects of society, are used to quantify the underlying drivers. Attributable child deaths, as well as reductions in child mortality as the result of achieving a range of, mostly environmentrelated SDG targets are determined using the population health model. Here, the GISMO health model is described, as well as the health risk factors included and how they are linked to the IMAGE integrated assessment model, and the various scenarios with their underlying assumptions.

\subsection{The GISMO health model}

The GISMO health model describes the causal relationship between health risk factors, morbidity and mortality, based on a multi-state approach, distinguishing risk exposure, disease incidence and death (WHO, 2002; Cairncross and Valdmanis, 2006). The model is used to assess future developments in child mortality attributable to selected risk factors. Calculations were made for 27 world regions (Hilderink et al., 2008), and results were aggregated to four regions, i.e. Sub-Saharan Africa, South Asia, East and Southeast Asia and the Rest of the World. The focus of the analysis was on the most important environmental health risks for children under the age of five that relate to infectious diseases (pneumonia, diarrhoea and malaria) and nutritional deficiencies. The multi-state approach was used for the infectious diseases. Mortality related to nutritional deficiencies was calculated, directly, by scaling base-year (2010) mortality related to nutritional deficiencies with projected future trends in child underweight (see Section 2.2.1). The model was calibrated to data from the Global Burden of Disease Study 2013 (Forouzanfar et al., 2015; Naghavi et al., 2015; Vos et al., 2015).

The mortality rate $(M R)$ in year $t$ of a specific disease $(d)$ per region $(r)$, sex $(s)$ and age groups $(a)$ is a multiplication of the incidence rate $(I R)$, i.e. the number of disease cases per year as a fraction of the subpopulation, and the case fatality rate $(C F R)$, i.e. the proportion of the sub-population dying from a specific disease:

$M R_{t, r, d, s, a}=I R_{t, r, d, s, a}{ }^{*} C F R_{t, r, d, s, a}$

Future developments in both IR and CFR are determined as a multiplication of three components: 1) base-year risk-free CFR and IR; 2) future developments in risk-free CFR and IR; and 3) increased CFR and IR because of future developments in the exposure to specific health risk factors: 
$I R_{t, r, d, s, a}=\frac{I R_{2010, r, d, s, a}}{R R_{I R, 2010, r, d, s, a}} * \frac{a_{I R, d, s, a} e^{-b_{I R, d, s, a} * G D P p c_{t, r}}}{a_{I R, d, s, a} e^{-b_{I R, d, s, a} * G D P p c_{2010, r}}} * R R_{I R, t, r, d, s, a}$

$C F R_{t, r, d, s, a}=\frac{C F R_{2010, r, d, s, a}}{R R_{C F R, 2010, r, d, s, a}} * \frac{a_{C F R, d, s, a}{ }^{*} e^{-b_{C F R, d, s, a} * G D P p c_{t, r}}}{a_{C F R, d, s, a}{ }^{*} e^{-b_{C F R, d, s, a} * G D P p c_{2010, r}}} * R R_{C F R, t, r, d, s, a}$

Exposure $(P)$ to health risk factors ( $r f$ ) and different exposure categories ( $i$ ), expressed as a percentage of the population or age group, are included by using relative risk (RR) ratios based on epidemiological studies. RR ratios indicate the increased risk of falling ill or dying from being exposed to a certain risk factor, as compared to a situation with no increased risks $(R R=1)$. The $R R$ ratio of total mortality associated with a specific risk factor is interpreted here as a multiplication of the relative risk of incidence with that of case fatality (Niessen, 2002). If exposure to more than one risk factor is related to a certain disease, the total effect of these risk factors is calculated in a multiplicative way:

$R R_{I R, t, r, d, s, a}=\prod_{r f} \sum_{i}\left(R R_{I R, i, r f, d, s, a}{ }^{*} P_{t, r, i, r f, d, s, a}\right)$

$R R_{C F R, t, r, d, s, a}=\prod_{r f} \sum_{i}\left(R R_{C F R, i, r f, d, s, a} * P_{t, r, i, r f, d, s, a}\right)$

The original GISMO health model distinguished between base rates and excess rates, for incidence and case fatality (Niessen and Hilderink, 1997; Hilderink et al., 2008). The base rates reflect minimum levels of incidence rates and case fatality rates without exposure to any health risk factor and without excess incidence or case fatality. Excess rates occur under interregional variation in risk-free rates. Recalibrating the model to the data from the Global Burden of Disease Study 2013 made it difficult to obtain good estimates of the base incidence and case fatality rates for the diseases included. Furthermore, it can be argued that for infectious diseases, without risk exposure, related mortality approaches zero. Therefore, in the updated and recalibrated model used here, the base rates and the excess rates were added together in projecting future health impacts.

Base-year risk-free rates are determined by dividing historical incidence and case fatality rates, by base-year RR ratios. Future developments in risk-free incidence and case fatality rates are determined, considering developments in regional health systems, using the trend in exponential regression of risk-free rates with gross domestic product per capita (GDPpc). The disease-specific regression parameters $a$ and $b$ are estimated separately for the IR and CFR, for males and females, and for children aged $0-1$ and 1-4, using incidence and mortality data from Global Burden of Disease Study 2013 and RR ratios, as determined in the model (Formulas $3 \mathrm{a}$ and $3 \mathrm{~b}$ ), both for 2010. The regression parameters are assumed to be constant over time.

The effect of a single health risk factor on a specific disease or total attributable mortality is calculated as the Population Attributable Fraction (PAF; Ezzati et al., 2002):

$P A F_{r f, d, s, a}=\frac{\sum_{i=1}^{n} P_{i, r f, d, s, a} R R_{i, r f, d, s, a}-\sum_{i=1}^{n} P^{\prime}{ }_{i, r f, d, s, a} R R_{i, r f, d, s, a}}{\sum_{i=1}^{n} P_{i, r f, d, s, a} R R_{i, r f, d, s, a}}$

where $P_{i}$ is the exposed population fraction and $P_{i}$ the exposure distribution that would result in the lowest population risk. Mortality attributable to a cluster of independent and uncorrelated risk factors can also be calculated:

$P A F_{d, s, a}=1-\prod_{r f=1}^{n}\left(1-P A F_{r f, d, s, a}\right)$

\subsection{Health risk factors}

The GISMO model includes four important health risk factors for

\section{Health-risk factors}

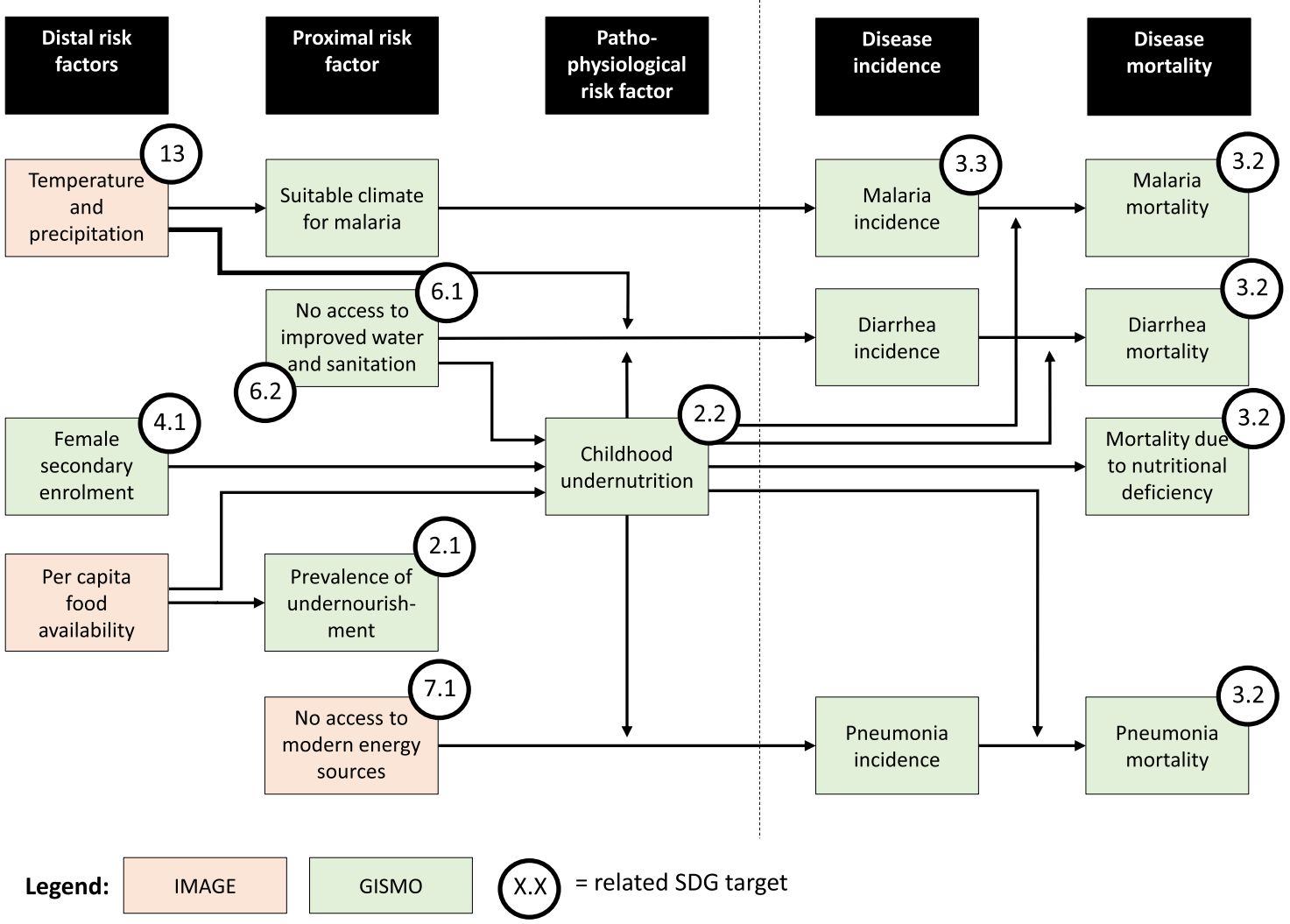

Fig. 1. Relations between health risk factors and child mortality outcomes, related SDG targets and linkages with the IMAGE model. 
children under the age of five: childhood undernutrition, no access to improved drinking water and sanitation, indoor air pollution and suitable climate for malaria vectors. Childhood undernutrition itself is not an environmental risk factor, but several of its underlying drivers are, such as climatic factors. Furthermore, undernutrition is largely interlinked with other environmental risk factors with respect to their impact on morbidity and mortality. Simultaneously, it is linked to socioeconomic determinants, including poverty and access to food.

Risk factors are structured according to their direct or indirect contribution to the occurrence of diseases and deaths in distal causes, proximal causes and pathophysiological causes (Fig. 1) (WHO, 2002; Ezzati et al., 2005). Distal risk factors influence proximal risk factors which, in turn, can affect pathophysiological causes of disease and death. A single factor can be influenced by several factors, and multiple factors can be influenced by one factor. Future developments in health risk factors were taken from scenario results from the integrated assessment model IMAGE3.0 (Stehfest et al., 2014) and the agro-economic model MAGNET (Woltjer and Kuiper, 2014).

The IMAGE3.0 framework simulates the global and regional environmental consequences of changes in human activities. The model includes a detailed description of energy and land-use systems and simulates most of the socio-economic parameters for 26 regions and most of the environmental parameters based on a geographical grid of $30 \times$ 30 or $5 \times 5$ arcminutes (depending on the variable).

MAGNET is a multi-regional, multi-sectoral, applied general equilibrium model, with a focus on agriculture and food markets. It uses information from IMAGE on land availability and suitability, on exogenous developments in crop and livestock production systems, and on changes in crop yields due to agricultural expansion on inhomogeneous land areas.

The following sections describe the calculations of the health risk factors determined in the GISMO model (green in Fig. 1) and their impact on health outcomes, i.e. disease-specific morbidity and mortality.

\subsubsection{Childhood undernutrition}

In the GISMO model, childhood undernutrition is indicated by child underweight, measured by weight-for-age. Child underweight is modelled by linear regression with average food intake, female enrolment in secondary education and access to clean drinking water, based on Smith and Haddad (2000). Base-year (2010) child underweight data are taken from FAO food security indicators (FAO et al., 2015), projected average food intake (kcal/cap/day) from MAGNET (Doelman et al., 2018), and projected access to clean drinking water and female enrolment in secondary education, from calculations within the GISMO model (see Section 2.2.2 and Supplementary Material Chapter S2, respectively).

Based on a normal distribution, the total number of underweight children is divided into groups of mild, moderate and severely underweight children (De Onis and Blossner, 2003). Undernutrition has both a direct and an indirect effect on mortality. The direct effect becomes visible through mortality related to nutritional deficiencies (including protein-energy malnutrition, iodine deficiency and iron-deficiency anaemia). Child mortality rates due to nutritional deficiencies, in the base year, are scaled using the projected trend in overall child underweight. Indirectly, undernutrition exacerbates the incidence of diarrhoea and pneumonia, and the risk of dying from malaria, diarrhoea and pneumonia. The effects are considered distinguishing differential relative risk ratios, for both incidence rates and case fatality rates (Table 1).

The GISMO model also calculates the prevalence of undernourishment (the fraction of the population below minimum level of dietary energy requirement), using a method proposed by the FAO (2008). It uses a lognormal distribution function determined by average food intake (kcal/cap/day) from MAGNET and a food distribution or inequality parameter (coefficient of variation). The coefficient of variation is a function of per capita GDP as used in Hasegawa et al. (2015)
Table 1

Relative risk ratios for different underweight levels on the incidence and total mortality of diarrhoea, pneumonia and malaria. Source: Edejer et al. (2005) and Fishman et al. (2004).

\begin{tabular}{llll}
\hline Disease & Underweight level & $\begin{array}{l}\text { RR incidence } \\
(95 \% \mathrm{CI})\end{array}$ & $\begin{array}{l}\text { RR mortality } \\
(95 \% \mathrm{CI})\end{array}$ \\
\hline diarrhoea & Mild & 1 & $2.32(1.93,2.79)$ \\
& Moderate & $1.23(1.12,1.35)$ & $5.39(3.73,7.79)$ \\
& Severe & $1.23(1.12,1.35)$ & $12.50(7.19,21.73)$ \\
Pneumonia & Mild & 1 & $2.01(1.63,2.47)$ \\
& Moderate & $1.86(1.06,3.28)$ & $4.03(2.67,6.08)$ \\
& Severe & $1.86(1.06,3.28)$ & $8.09(4.36,15.01)$ \\
& Mild & - & $2.12(1.48,3.02)$ \\
& Moderate & - & $4.48(2.20,9.15)$ \\
& Severe & - & $9.49(3.25,27.66)$ \\
\hline
\end{tabular}

${ }^{\mathrm{a}} \mathrm{RR}$ case fatality $=\mathrm{RR}$ mortality / RR incidence.

and the minimum dietary energy requirement is derived by aggregating the region specific sex-age energy requirements weighted by the proportion of each sex and age group in the total population, based on data from FAO (2008).

Base-year child underweight is input data that do not distinguish between underlying environmental and non-environmental factors. For future developments in child underweight, it is possible to attribute changes to some, but not all, environmental factors, including to developments in access to clean drinking water (GISMO) and to climate change impacts on average food intake (MAGNET). The analysis does not differentiate between environmental drivers of child underweight and other drivers. Instead, it reports environment-related child mortality with and without accounting for the impact of child underweight.

\subsubsection{No access to improved drinking water and sanitation}

The proportion of the population that lacks access to an improved drinking water source and improved sanitation was modelled separately for urban and rural populations and various levels of access (i.e. no access, improved access and household connection (Cairncross and Valdmanis, 2006)). The last level (household connection) was modelled for drinking water only. The access levels were modelled by applying linear regressions with GDP per capita, urbanisation rate and population density. Base-year (2010) access levels were taken from the Joined Monitoring Programme for water and sanitation (WHO/UNICEF, 2015). Developments in drinking water were assumed to be implemented ahead of sanitation. Incidence rates of diarrhoea increased dependent on the level of access to drinking water and sanitation facilities (Table 2), on the level of child underweight (Table 1) and on temperature increase (McMichael et al., 2004). Temperature increase was calculated as population-weighted average, using gridded population data from Van Vuuren et al. (2007) and gridded temperature data from IMAGE3.0 (Stehfest et al., 2014). The case fatality rates of diarrhoea were increased based on the level of child underweight (Table 1).

\subsubsection{Indoor air pollution}

Indoor air pollution (i.e. exposure to carbon monoxide and fine particle emissions) is caused by the use of traditional biomass for cooking and heating on open fires or traditional stoves. Access to modern sources of energy is used to indicate indoor air pollution. The model distinguishes between three levels of energy use: 1) traditional biomass and coal on traditional stoves; 2) traditional biomass and coal on improved stoves; and 3) modern fuels (electricity, natural gas, LPG, kerosene, modern biofuels and solar stoves). For the modern fuels, we made no distinction between stoves. The shares of the population with certain access levels were taken from the IMAGE3.0 model, based on urban and rural household incomes per quintile, fuel prices and potential subsidies on fuels and stoves (Daioglou et al., 2012). Incidence rates of pneumonia increased from exposure to indoor air pollution caused by cooking and heating using traditional biomass and coal, with 
Table 2

Determinant-specific relative risk of different exposure categories for the incidence of diarrhoea and pneumonia.

\begin{tabular}{|c|c|c|c|c|}
\hline Risk factor & Disease & Exposure category & Relative Risk & Source \\
\hline \multirow[t]{4}{*}{ Drinking water and sanitation } & \multirow[t]{4}{*}{ diarrhoea } & No improved water supply, no basic sanitation & 11.0 (low, high: $6.1,16.0$ ) & (Prüss-Üstün et al., 2004) \\
\hline & & Improved water supply, no basic sanitation & 8.7(low, high: $4.9,12.6$ ) & (Prüss-Üstün et al., 2004) \\
\hline & & Improved water supply, basic sanitation & 6.9 (low, high: $3.8,10.0$ ) & (Prüss-Üstün et al., 2004) \\
\hline & & Household connection water supply, basic sanitation & $2.5^{\mathrm{a}}$ & (Prüss-Üstün et al., 2004) \\
\hline \multirow[t]{3}{*}{ Household energy use for cooking and heating } & \multirow[t]{3}{*}{ Pneumonia } & Modern fuels & 1 & ? \\
\hline & & Traditional biomass and coal on traditional stoves & 2.3 (95\% CI: $1.9,2.7)$ & (Bruce et al., 2006) \\
\hline & & $\begin{array}{l}\text { Traditional biomass and coal on improved biomass } \\
\text { stoves }\end{array}$ & 0.35 (low, high: $0.1,0.6)^{\mathrm{b}}$ & (Hutton et al., 2006) \\
\hline
\end{tabular}

a Prüss-Üstün et al. (2004) did not conclude low and high estimates for this category.

b Reduction in RR for traditional stoves.

a lower increase for improved stoves than for tradition stoves (Table 2). Incidence rates and case fatality rates were further associated with child underweight levels (Table 1).

\subsubsection{Suitable climate for malaria vectors}

Malaria vectors - the mosquitoes spreading the infection - can only survive in a climate with high average temperatures, no frost and enough precipitation. The model uses these climatic factors to identify malaria-prone areas (Craig et al., 1999). For each climatic factor (average temperature, frost occurrence, precipitation), a fuzzy suitability index was calculated, with total climatic malaria suitability being determined by the lowest of these three indices. The individual factors were calculated at $30 \times 30$ arcminutes grid level, using temperature and precipitation projections from IMAGE3.0. The regional population at risk of malaria was estimated as the population-weighted average over the grid cells, using gridded population data (Van Vuuren et al., 2007). Potential malaria incidence was then determined by multiplying the regional population at risk with a fixed uniform incidence rate for each malaria endemicity category (low and high), for urban and rural areas (Table 3). Incidence rates of malaria were projected using base-year malaria incidence and the trend in potential malaria incidence, decreased by the level of insecticide-treated mosquito nets (ITN) and indoor residual spraying (IRS). ITN and IRS levels were increased with increasing GDP per capita. The case fatality rates were increased by child underweight levels (Table 1).

\subsection{Scenarios}

The analyses were based on two sets of scenarios: 1) three explorative scenarios to assess the range in future child mortality and in the attributable share related to environmental risk factors; and 2) two normative scenarios to assess reduction in child mortality as the result of achieving a range of mostly environment-related SDG targets (Table 4). The scenarios build on the IMAGE implementation of the SSPs (Van Vuuren et al., 2017b; Doelman et al., 2018). The SSPs are five distinct global pathways describing the future evolution of key aspects of society (Riahi et al., 2017; Van Vuuren et al., 2017a). They have been developed to assess future challenges for mitigation and adaptation to climate change, but as they are formulated relatively broadly and cover a wide range of possible futures, they are also used extensively for other

Table 3

Basic malaria incidence rates, by world region and endemicity category (Korenromp, 2005).

\begin{tabular}{llll}
\hline Region & Malaria endemicity & \multirow{2}{*}{ Rural } & \multirow{2}{*}{ Urban } \\
\hline Sub-Saharan Africa (excl. southern Africa) & High-endemic & 1.91 & 0.6 \\
& Low-endemic & 0.5 & 0.5 \\
Southern Africa & All endemic areas & 0.029 & 0.029 \\
Outside SSA & Hyper-endemic & 1.09 & 0.33 \\
& Meso-endemic & 0.45 & 0.14 \\
\hline
\end{tabular}

fields of environmental research and assessment. Each SSP contains a quantification of future developments in population (KC and Lutz, 2017), urbanisation (Jiang and O'Neill, 2017) and economic development (Dellink et al., 2017), and a descriptive storyline to guide further model parametrisation (O'Neill et al., 2017), including extended storylines that describe possible consequences for health risks and health systems (Ebi, 2014; Sellers and Ebi, 2018). ${ }^{2}$

For the explorative scenarios, we looked at SSP1, SSP2 and SSP3 (see Table 4). SSP2 is a middle-of-the-road scenario, describing a continuation of current trends. SSP1 describes a world that makes good progress towards sustainability, which is thus more optimistic than SSP2 with respect to human development and vulnerability. In contrast, SSP3 describes a world that is more fragmented, moving away from sustainability, which is thus more pessimistic than SSP2 with respect to human development and vulnerability. Projections of regional child mortality, under these three SSP scenarios, were based on demographic projections by KC and Lutz (2017), who base their mortality projections on global conditional convergence of life expectancy at birth. Over time, country-level life expectancy will approach that in regional front runner countries, which themselves are slowly approaching the life expectancy level of Japan, the global front runner. For Japan, SSP2 assumes a constant increase of two years in life expectancy, per decade. The SSP1 and SSP3 scenarios assume life expectancy in Japan to increase by one year per decade faster and slower, respectively, than under SSP2. Corresponding to each life expectancy, life tables were generated by interpolating the life tables from UN's World Population Prospects 2010 (UN, 2011). In cases where life expectancy was higher than the range in WPP2010, mortality rates above the age of 60 were extrapolated. Survival ratios were extracted from the resulting life tables and further decomposed into six sets of education-specific survival ratios, using iterative simulation for assumed mortality differentials at age 15, and mapped to the various SSP scenarios. To estimate underfive mortality rates, after applying the survival ratios, we used a weighted average of the death rate among newborns and those aged 0 to 4. Projections of attributable child mortality were determined using the GISMO health model in combination with the IMAGE implementation of the three SSPs (see Table 5).

The two normative scenarios build on the SSP2 (middle-of-the-road) scenario (see Tables 4 and 5). The policies in these two scenarios are stylised in the sense that they do not consider socio-economic and environmental constraints. Under the SSP2_FullAccess scenario, the SDGs targets on hunger, drinking water and sanitation and modern sources of energy are all achieved by 2030 . The hunger target is achieved by increasing total food availability (Kcal/cap/day) in order to bring the prevalence of undernourishment of the whole population to zero. The SSP2_QualityAccess scenario extends the SSP2_FullAccess scenario by also addressing quality aspects of access, as well as further measures that mitigate the effect of poor access on disease incidence and

\footnotetext{
${ }^{2}$ The socioeconomic data are publicly available from the interactive SSP web database at https://secure.iiasa.ac.at/web-apps/ene/SspDb
} 
Table 4

Scenario description.

\begin{tabular}{|c|c|c|}
\hline & Scenario name & Description \\
\hline \multirow[t]{3}{*}{ Explorative scenarios } & SSP1 (Sustainability) & $\begin{array}{l}\text { A world that makes relatively good progress towards sustainability, with sustained efforts to achieve development } \\
\text { goals, while reducing resource intensity and fossil fuel dependency. Educational and health investments } \\
\text { accelerating the demographic transition, leading to relatively low mortality. Economic development is high and } \\
\text { population growth is low. }\end{array}$ \\
\hline & SSP2 (Middle of the Road) & $\begin{array}{l}\text { A world in which trends typical of recent decades continue (business as usual), with some progress towards } \\
\text { achieving development goals, reductions in resource and energy intensity at historic rates, and slowly decreasing } \\
\text { fossil fuel dependency. Fertility and mortality are intermediate and also population growth and economic } \\
\text { development are intermediate. }\end{array}$ \\
\hline & SSP3 (Regional Rivalry) & $\begin{array}{l}\text { A world that is fragmented, characterised by extreme poverty, pockets of moderate wealth and a bulk of countries } \\
\text { that struggle to maintain living standards for a strongly growing population. The emphasis is on security at the } \\
\text { expense of international development. Mortality is high everywhere, while fertility is low in rich OECD countries } \\
\text { and high in most other countries. Economic development is low and population growth is high. }\end{array}$ \\
\hline \multirow[t]{2}{*}{ Normative scenarios } & SSP2_FullAccess (Based on SSP2) & $\begin{array}{l}\text { A scenario that builds on the SSP2 scenario, but in which, by } 2030 \text { the SDG targets on hunger (Target 2.1), access to } \\
\text { water and sanitation (Target } 6.1 \text { and } 6.2 \text { ) and access to modern energy sources (Target 7.1) are achieved. }\end{array}$ \\
\hline & SSP2_QualityAccess (Based on SSP2) & $\begin{array}{l}\text { An extension of the SSP2 FullAccess scenario, with further measures to improve the quality of access to water and } \\
\text { energy (SDG target } 6.1 \text { and } 7.1 \text { ), universal secondary female education (SDG target } 4.1 \text { ) and advanced malaria } \\
\text { control behavioural measures (SDG target } 3.3 \text { ) and climate policy for keeping the increase in the global mean } \\
\text { temperature below } 2{ }^{\circ} \mathrm{C} \text {, compared to pre-industrial levels (SDG 13). }\end{array}$ \\
\hline
\end{tabular}

mortality. This includes the following: keeping the increase in the global mean temperature below $2{ }^{\circ} \mathrm{C}$, compared to pre-industrial levels (Paris Agreement); by 2030, for all households to have access to a piped drinking water source; the use of biomass, including from improved stoves, to be completely phased out; for all girls to be enrolled in secondary education; and full coverage of insecticide-treated mosquito nets (ITN) and indoor residual spraying (IRS) to combat malaria. With respect to climate policy, temperature and precipitation maps were taken from the IMAGE SSP2 $2.6 \mathrm{~W} / \mathrm{m} 2$ scenario (Van Vuuren et al., 2017b). Overall child mortality as a result of these policies was calculated by subtracting the reductions in attributable mortality, as determined with the GISMO health model, from overall child mortality under the SSP2 scenario, as determined using demographic data from KC and Lutz (2017).

Our model-based analysis is subject to a range of uncertainties, including future socio-economic developments and the extent to which health risk factors impact disease incidence and death. Implications of uncertainty in future socio-economic developments on child mortality and attributable deaths were analysed by using the three SSP scenarios (Table 4). No uncertainty values were attached to the scenario results with respect to overall child mortality rates and projections of hunger and access to water, sanitation and energy. This article presents only a range of possible outcomes, with SSP1 and SSP3 at the respective lower and higher ends of that range.

To quantify the link between health risk factors and disease incidence and death, the GISMO model uses relative risk (RR) ratios. The assessment of attributable mortality takes uncertainty in the RR ratios into account, using Monte Carlo sampling $(\mathrm{N}=1000)$ on the full uncertainty ranges of the various $\mathrm{RR}$ values. For the RR values for malaria, with respect to climate suitability on incidence rate, no estimates of uncertainty were available from Korenromp (2005). For the other risk factors, the ranges indicated in Tables 1 and 2 were used. The RR ratios were interpreted as absolute minima and maxima, to truncate the lognormal and normal shaped uncertainty distributions, respectively, which were employed for sampling the RR values. In sampling, the various relative risks were assumed to be uncorrelated. The Monte Carlo sampling concludes a 95\% confidence interval (CI) for attributable mortality for the five scenarios and the child mortality rates for the two normative scenarios.

\section{Results}

\subsection{Future developments in child mortality}

Globally, child mortality is projected to decrease between 2010 and
2030 under SSP1 (48\%) and SSP2 (25\%) and to increase under SSP3 (18\%), from 59 child deaths per 1000 live births in 2010 (UN, 2011) to a respective 31, 45 and 71 by 2030 under SSP1, SSP2 and SSP3 (Fig. 2). As a result, the SDG target on child mortality (at least as low as 25 child deaths per 1000 live births) will not be achieved, at the global level, under any of the three SPP scenarios, mainly due to persistent, high levels of child mortality in Sub-Saharan Africa, but to a lesser extent also in South Asia. By 2050, 20 years later than the official SDG target year, the target will only be achieved globally under SSP1. In this optimistic scenario, even Sub-Saharan Africa comes close to achieving it. Under the other two scenarios, even by 2050, the target remains largely out of reach. Lange and Klasen (2017) already concluded that this target is overly ambitious for countries in Sub-Saharan Africa, as it is an absolute target rather than a relative one.

It should be noted that target 3.2 is to reduce the child mortality rate to at least as low as 25 deaths per 1000 live births, in all countries, while the modelling framework we used provides projections for aggregated regions. As many developed countries already have child mortality rates significantly below the target level, all countries achieving the target actually results in a global average child mortality rate of well below 20 (You et al., 2015). As a result, many countries, especially in Sub-Saharan Africa, will also be largely off track under SSP1 by 2050 .

\subsection{The role of environmental factors}

In relative terms, the total number of underweight children and those without access to improved drinking water, improved sanitation and modern sources of energy is projected to decrease significantly towards 2030. In absolute terms, however, by 2030, many children will still be living without such adequate access to food, water and energy, mainly those in Sub-Saharan Africa and South Asia and - to a lesser extent - also in East and Southeast Asia (Fig. 3). The related SDG targets on eradicating hunger and achieving universal access to improved drinking water, improved sanitation and modern sources of energy will not be achieved in any of the three scenarios.

Depending on the SSP scenario, by 2030 , between 48 and 108 million children are projected to be underweight, 18 to 44 million children will not have access to improved drinking water, 80 to 201 million children will live without access to improved sanitation, and 30 to 226 million children will live without access to modern sources of energy for cooking and heating. Child underweight is projected to remain a problem in Sub-Saharan Africa and South Asia, while a lack of access to improved drinking water is projected to be concentrated mainly in Sub-Saharan Africa. Access to improved sanitation and 
modern sources of energy for cooking remains a problem in both South Asia and Sub-Saharan Africa and - to a lesser extent - also in East and Southeast Asia. Large improvements in absolute numbers are projected under SSP1 for all regions, while SSP3 projects almost no improvements and even a deterioration in the access to modern sources of energy. For SSP3, this is the result of high population growth, slow economic development and persistent inequality.

As a result of projected improvements in child underweight, in access to improved drinking water, improved sanitation and modern energy sources, and in overall development levels, attributable mortality is projected to decrease under all three SSP scenarios (Fig. 4). For East and Southeast Asia and the Rest of the World, attributable mortality is projected to decrease more rapidly and, except under SSP3, will be almost eliminated by 2050. Strong reductions are also projected for Sub-Saharan Arica and South Asia. Assuming nominal values for the RR ratios, globally, the share of the discussed health risk factors in total child mortality for the three SSP scenarios is projected to decrease from around $25 \%$ in 2010 to between $14 \%$ and $16 \%$ by 2030 and $3 \%$ and $10 \%$ by 2050 . In 2030 , child underweight is projected to be responsible for $8 \%$ to $9 \%$ of total global child deaths, the lack of improved drinking water and sanitation for $3 \%$ to $4 \%$, indoor air pollution for $2 \%$ to $3 \%$ and exposure to malaria vectors for $3 \%$ to $4 \%$. The last three exclude the increased effect of child underweight. As discussed in Section 2.2, child underweight is affected by both environmental and non-environmental factor. When excluding mortality solely related to child underweight, the shares of environmental health risk factors is projected to decrease, from $14 \%$ in 2010 to $8 \%$ to $10 \%$ by 2030 and $1 \%$ to $6 \%$ by 2050 .

\subsection{Improvements in child mortality from achieving specific SDG targets}

Under the SSP2_FullAccess scenario, the SDG targets on hunger (target 2.1), access to an improved drinking water source (target 6.1), access to improved sanitation (target 6.2), and access to modern energy sources for cooking and heating (target 7.1) are assumed to be achieved by 2030 . Achieving the hunger target decreases the mortality that is attributable to child underweight by $75 \%$, by 2030 , compared to the reference SSP2 scenario (Table 6). The remaining cases of underweight can largely be attributed to food utilisation - which in our modelling framework is linked to female education levels (Smith and Haddad, 2000; Marmot, 2010). Achieving universal access to improved drinking water and sanitation is projected to reduce attributable mortality by $44 \%$, by 2030 , with further mortality reductions possible through measures of hygiene and by replacing public standpipes and boreholes by household connections to a drinking water supply system (PrüssÜstün et al., 2009). Achieving universal access to modern energy sources is projected to decrease attributable mortality by $62 \%$ by 2030 , with further mortality reductions possible through increased ventilation and a complete transition to modern fuels, such as electricity and LPG, also replacing improved biomass stoves (Hutton et al., 2006). Finally, mortality due to malaria is projected to reduce by $35 \%$, as result of the significant reductions in child underweight, with further improvements possible by combatting malaria-carrying mosquitoes with insecticidetreated mosquito nets and indoor residual spraying (Morel et al., 2005).

As a result of all these interventions, global child mortality is projected to decrease by around 433 thousand child deaths by 2030 (95\% CI: 370 to 541 thousand), as compared to the reference SSP2 scenario. The difference between both projections is around 183 thousand child deaths, when excluding mortality exclusively related to child underweight. By far the largest decrease is projected for Sub-Saharan Africa (see SI). By 2050, improvements are projected to be much smaller, with only a decrease of around 45 thousand child deaths (95\% CI: 45 to 47 thousand), compared to the reference SSP2 scenario. Under SSP2, access levels by 2050 are projected to be relatively high already, and thus attributable mortality will be low. Overall, global child mortality by 2030 is projected to be reduced by $7.6 \%$ (95\% CI: 6.4\%-8.8\%), from 45 

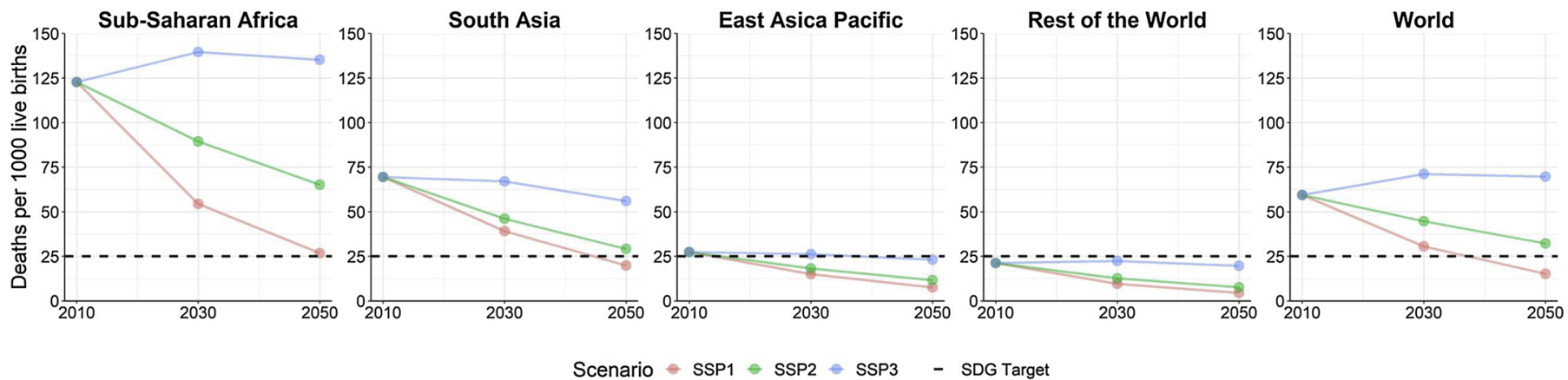

Fig. 2. Under-five mortality rate in the three SSP scenarios.

child deaths per 1000 live births under SSP2, to around 40 under the SSP2_FullAccess scenario.

Under the SSP2_QualityAccess scenario, higher standards of access to drinking water and modern sources of energy are implemented, as well as universal secondary female education (SDG target 4.1) and advanced malaria control (related to SDG target 3.3). As a result, remaining environmental health risk exposure is almost eliminated and global child mortality is projected to be reduced with around 733 thousand child deaths by 2030 ( $95 \%$ CI: 585 to 938 thousand) and 110 thousand by 2050 (95\% CI: 86 to 138 thousand), as compared to the reference SSP2 scenario. When excluding mortality exclusively related to child underweight, total avoided child deaths compared to the reference SSP2 scenario is projected to be around 444 thousand by 2030 (95\% CI: 343 to 563 thousand).

Overall, global child mortality by 2030 is projected to be $12.9 \%$ (95\% CI: $12.8 \%-13.0 \%$ ) lower under the SSP2_QualityAccess scenario than under the reference SSP2 scenario. Again, Sub-Saharan Africa takes the lion share of avoided child deaths (see SI). Further improved energy and water services eliminate most of the attributable mortality. Furthermore, achieving universal secondary female education significantly improves the utilisation of food - reducing child underweight due to better nutrition - especially in Sub-Saharan Africa. Under the reference SSP2 scenario secondary school enrolment for girls is projected to be around $60 \%$ by 2030 . Reduced climate change decreases the expansion of malaria-prone areas and lowers the risk of diarrhoea. It should however be noted that, by 2030, the effects of climate change mitigation will still be small and will only become significant in the second half of this century. Finally, insecticide-treated mosquito nets and indoor residual spraying reduces malaria incidence with around 75\% (Morel et al., 2005).

\section{Discussion}

The analysis shows that the SDG target on child mortality will not be achieved under any of the three SSP scenarios analysed and that environmental health risk factors will still be relevant in 2030 . Furthermore, a significant part of the reduction in child mortality needed to achieve the 2030 target could be realised by achieving the SDG targets on child nutrition, access to improved drinking water and sanitation, access to modern energy sources, and advanced malaria control.

Our projections of global child mortality are broadly in line with other studies that assume trends in cause-specific mortality over the 2000-2013 period will continue up to 2030 (Liu et al., 2015; You et al., 2015; Fullman et al., 2017). Their 2030 projections range between 23 and 32 child deaths per 1000 live births (i.e. a 38\%-56\% reduction, compared to 2010), which is at the lower end of our range, close to the scenario with sustained efforts to achieve development goals (SSP1). Part of this difference can be explained by differences between historic population data used in this study and in the other studies. The SSP population projections were developed in 2012 and are built on demographic data from UN (2011). The other studies have built their projections on more recent demographic data, with updated insight on historical developments, including a much more rapid reduction in under-five mortality between 2000 and 2010 . The most recent estimate on the 2010 child mortality rate is 52 deaths per 1000 live births (UN, 2017), compared to 59 in UN (2011). Nevertheless, our projected improvements in child mortality rates $(52 \%$ and $25 \%$ reduction compared to 2010, under SSP1 and SSP2, respectively) and the conclusion that the world is not on track to achieve the SDG target on child mortality are in line with the findings in the studies listed above.

\section{Child underweight}

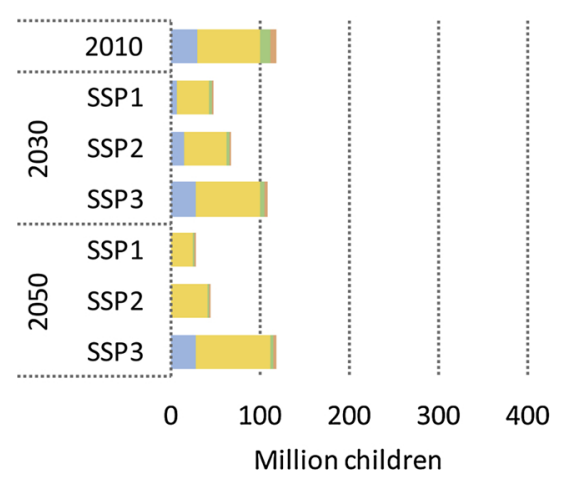

Sub-Saharan Africa

\section{No access to improved drinking water}

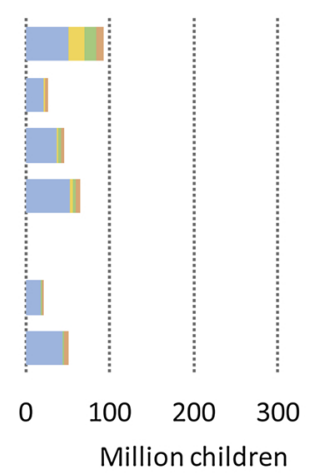

No access to improved sanitation

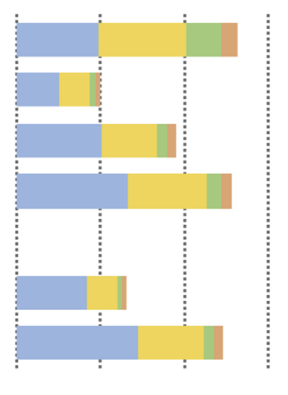

400

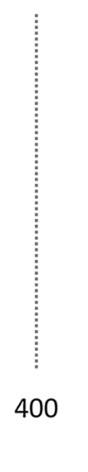

\section{South Asia}

No access to modern sources of energy

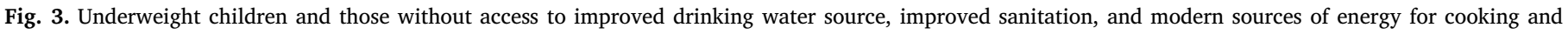
heating, in the three SSP scenarios. 


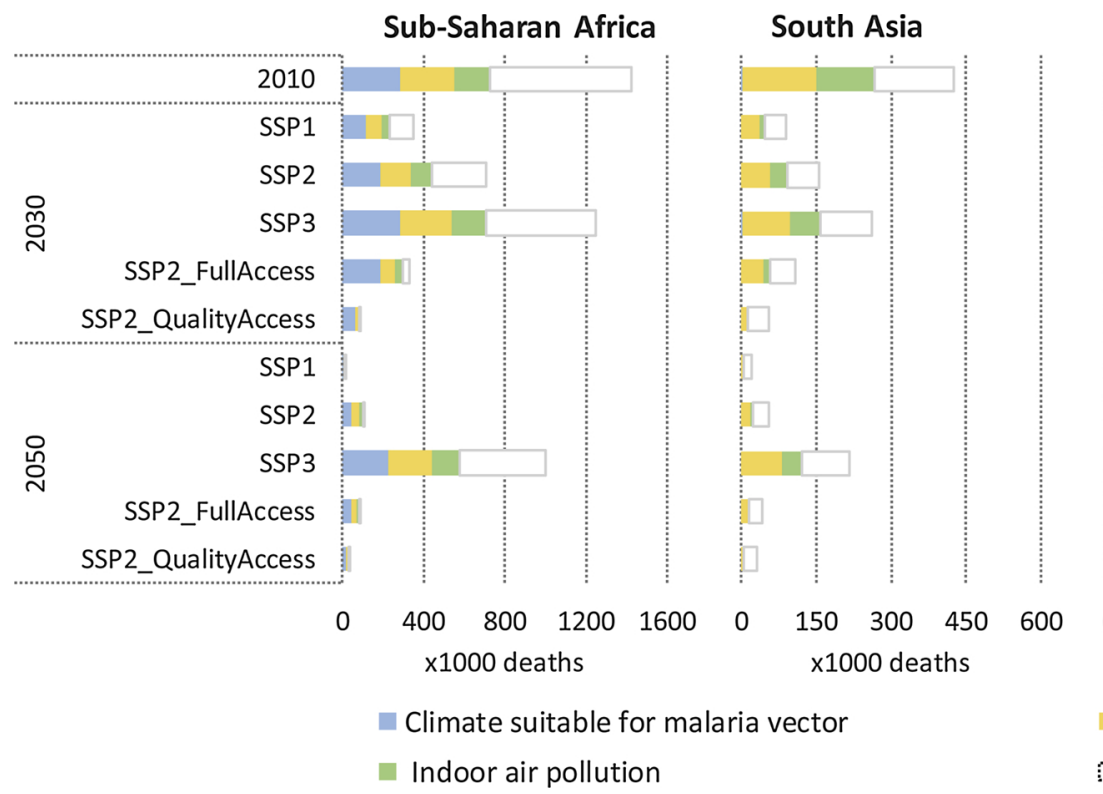

East and Southeast Asia Rest of the World

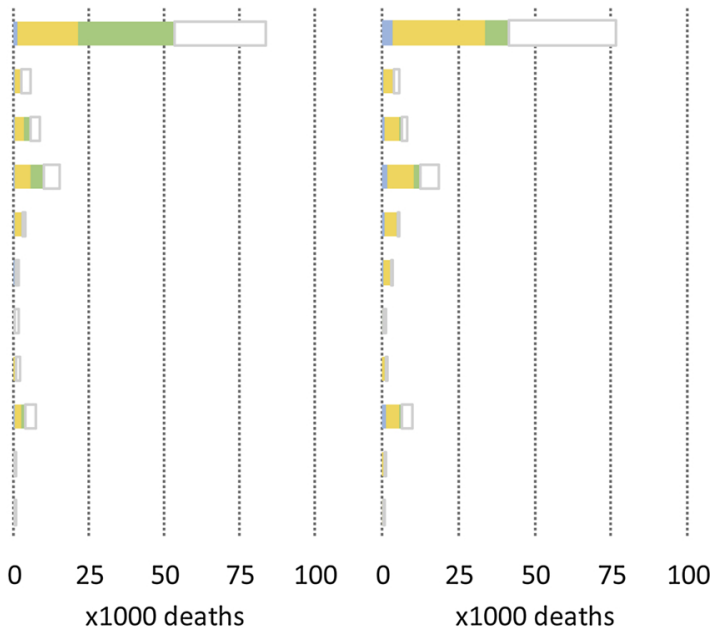

No access to improved drinking water and sanitation Childhood undernutrition *

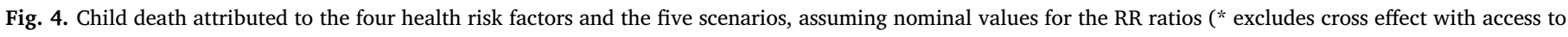
improved drinking water and sanitation and with indoor air pollution).

The relative differences between the three SSP projections, as well as the trends in attributable mortality, are in line with the qualitative discussion about potential SSP results on human health by Sellers and Ebi (2018). They argue that the SDG target on child mortality could be achieved under SSP1, as health systems are likely to deliver higher quality and more equitable services and fewer deaths associated with preventable causes, such as undernutrition, malaria and diarrhoeal diseases. In contrast, for SSP3 they argue that the mortality transition stalls nearly completely, with undernutrition, malaria, and diarrhoeal diseases continuing as major causes of death, particularly among young children.

Our study does have certain limitations, however. The assessment of attributable mortality assumes an independent occurrence of the risk factors included. This does not completely reflect reality, as very often these risk factors are related with, for example, poverty, and therefore might cluster among the poor population. However, data on how these factors correlate are lacking. Furthermore, this study does not account for competing mortality risks, i.e. elimination of a single risk could cause an increase in the mortality risks related to other factors. This might result in a small overestimation of the effect of specific interventions. Also, several risk factors are only included indirectly or largely aggregated. For example, access to clean cooking is used in our study as a binary parameter (yes or no), while the overall impact on household level is actually determined by the related smoke (i.e. the
$\mathrm{PM}_{2.5}$ concentration level), which in turn depends on the type of fuel, the type of cookstove and the way it is used. Finally, our study does not differentiate between environmental and non-environmental drivers of undernutrition. This is difficult for the base year, because of data limitations, but the modelling framework does allow for future changes in child underweight to be attributed to some, but not all, environmental factors, including access to improved drinking water and climate change. The projected share of environmental factors in total child mortality is therefore overestimated when including child underweight, while excluding child underweight results in an underestimation of the role of environmental risk factors.

\section{Conclusions}

In this study, we examined the role of environmental risk factors in future developments in global child mortality by addressing cross-sectoral relationships between various SDGs. By linking a multi-state health model, that distinguishes risk exposure, disease and death, to an integrated assessment model that addresses future developments in drivers and impacts of global environmental change, we obtained key insights into the synergies between environment-related SDG targets and the SDG target on child mortality. By including mortality related to nutritional deficiencies, pneumonia, diarrhoea and malaria, around $36 \%$ of global child deaths in 2013 were covered (Naghavi et al., 2015).

Table 6

Global attributable child mortality and global under-five mortality rate, in 2030.

\begin{tabular}{|c|c|c|c|c|c|c|}
\hline & $\begin{array}{l}\text { Suitable climate for } \\
\text { malaria vectors }{ }^{\mathrm{a}} \\
\mathrm{x} 1000 \text { deaths }\end{array}$ & $\begin{array}{l}\text { No access to improved drinking } \\
\text { water and sanitation } \\
\text { x1000 deaths } \\
(95 \% \mathrm{CI})\end{array}$ & $\begin{array}{l}\text { Indoor air } \\
\text { pollution } \\
\text { x1000 deaths } \\
(95 \% \mathrm{CI})\end{array}$ & $\begin{array}{l}\text { Childhood } \\
\text { undernutrition } \\
\text { x1000 deaths } \\
(95 \% \mathrm{CI})\end{array}$ & $\begin{array}{l}\text { Total attributable child } \\
\text { death } \\
\text { x1000 deaths } \\
(95 \% \mathrm{CI})\end{array}$ & $\begin{array}{l}\text { Under-five mortality } \\
\text { rate } \\
\text { deaths per } 1000 \text { live } \\
\text { births } \\
(95 \% \mathrm{CI})\end{array}$ \\
\hline SSP1 & 113 & $122(88,163)$ & $47(31,68)$ & $230(202,280)$ & $447(375,549)$ & 30.6 \\
\hline SSP2 & 187 & $217(158,289)$ & $142(99,192)$ & $488(426,602)$ & $878(725,1092)$ & 44.6 \\
\hline SSP3 & 288 & $363(261,487)$ & $237(166,326)$ & $961(833,1213)$ & $1544(1266,1967)$ & 71.1 \\
\hline SSP2_FullAccess & 187 & $122(65,185)$ & $54(30,82)$ & $123(104,152)$ & $445(355,551)$ & $41.3(40.7,41.8)$ \\
\hline SSP2_QualityAccess & 65 & $37(36,40)$ & $0(0,0)$ & $50(46,58)$ & $145(140,154)$ & $38.9(38.8,38.9)$ \\
\hline
\end{tabular}

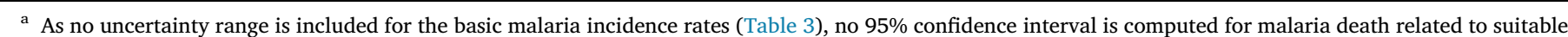
climate. Uncertainty in malaria death related to malnutrition is included in childhood undernutrition.

b Total child mortality attributable to child underweight, including the increased effects on incidence and case fatality for malaria, diarrhoea and pneumonia. Attributable deaths can thus not simply be summed. 
The analysis shows that the SDG target on reducing global child deaths, in all countries, to at least as low as 25 per 1000 live births, by 2030, will not be achieved under any of the three SSP scenarios analysed. This is mainly due to persistent high mortality rates in SubSaharan Africa and to a lesser extent also in South Asia. Global child mortality is projected to decrease from 59 deaths per 1000 live births in 2010 to 45 by 2030 under SSP2, and a respective 31 and 71 under SSP 1 and SSP3. Only under SSP1, the scenario with sustained efforts to achieve development goals, the target is projected be achieved at the global level before 2050. However, as large inequalities remain and many high income countries already have child mortality levels significantly below 25 per 1000 live births, the SDG target will also not be achieved by many countries in Sub-Saharan Africa by 2050 under SSP1.

The SDG targets on hunger and access to drinking water, sanitation and energy are also not achieved under any the three SSP scenarios. Although relatively large improvements in childhood undernutrition, access to improved drinking water, improved sanitation and modern energy sources, and malaria exposure are projected, together, these health risk factors still account for $14 \%$ to $16 \%$ of total child mortality by 2030 (or $8 \%-10 \%$ when excluding nutrition-related mortality). In general, these health risks could be avoided. Developed countries have already shown that, with the right policies and investments, such health risks can be almost completely eradicated, and there are many examples of developing countries successfully combating these risks.

Under SSP2, with nominal values for the relative risk ratios, achieving specific environment-related SDG targets (i.e. eradicating hunger and achieving universal access to improved drinking water and sanitation and to modern energy sources) results in a reduction in global child death of 433 thousand by 2030 ( $8 \%$ of total child mortality). Furthermore, by also taking the broader socio-economic context into account - including higher standards of access to water and energy, universal secondary female education and advanced malaria control global child mortality is projected to be reduced with around $13 \%$ by 2030, avoiding 733 thousand child deaths (444 thousand when excluding nutrition-related mortality), with by far most of these improvements being achieved in Sub-Saharan Africa. As a result, removing these health risks will reduce global child mortality by 2030 , from 45 to 39 child deaths per 1000 live births. To further reduce child mortality, also health promotion and health care need to be addressed. Their impact was not included in our analysis.

Overall, from the analysis can be concluded that a significant share of the reduction in child mortality that is needed to achieve the related SDG target could be achieved by policies in other sectors, such as in food, water and energy sectors. For example, more than $25 \%$ of the targeted child mortality reductions in Sub-Saharan Africa can be achieved through SDG-related policies on food, water and energy. Thus, in addition to direct health investments, child health could also be improved by reducing environmental risk factors. This would require a shift towards fully integrated approaches to health that include all related sectors (Whitmee et al., 2015; Queenan et al., 2017). The SDGs offer a framework and unique opportunity to do so.

\section{Acknowledgments}

The authors thank Anne ten Hove and Jan Wijbe Hoekstra for their early work on the GISMO model and Joan Williams of the Institute for Health Metrics and Evaluation (IHME) for providing the incidence data of the Global Burden of Disease Study 2013. The work benefitted from funding by the European Horizon 2020 research programme as part of the CD-LINKS project (Linking Climate and Development Policies-Leveraging International Networks and Knowledge Sharing) under grant agreement No. 642147. Louis Niessen is supported by the NIHR Global Health Research Unit 'IMPALA'(grant number 16/136/35). The National Institute of Health Research commissioned 'IMPALA' using Official Development Assistance (ODA) funding. The views expressed in this publication are those of the authors and not necessarily those of the funders.

\section{Appendix A. Supplementary data}

Supplementary material related to this article can be found, in the online version, at doi:https://doi.org/10.1016/j.gloenvcha.2019.05. 009.

\section{References}

Black, R.E., Victora, C.G., Walker, S.P., Bhutta, Z.A., Christian, P., et al., 2013. Maternal and child undernutrition and overweight in low-income and middle-income countries. Lancet 382 (9890), 427-451.

Bruce, N., Rehfuess, E., Mehta, S., Hutton, G., K. S, et al., 2006. Indoor Air Pollution. In: Jamison, D.T., Breman, J.G., Measham, A.R. (Eds.), Disease Control Priorities in Developing Countries, 2nd edition. The International Bank for Reconstruction and Development/The World Bank, Washington (DC).

Cairncross, S., Valdmanis, V., 2006. Water Supply, Sanitation, and Hygiene Promotion. Oxford University Press, New York.

Craig, M.H., Snow, R.W., le Sueur, D., 1999. A climate-based distribution model of malaria transmission in Sub-Saharan Africa. Parasitol. Today 15 (3), 105-111.

Daioglou, V., van Ruijven, B.J., van Vuuren, D.P., 2012. Model projections for household energy use in developing countries. Energy 37 (1), 601-615.

De Onis, M., Blossner, M., 2003. The World Health Organization global database on child growth and malnutrition: methodology and applications. Int. J. Epidemiol. 32 (4), 518-526.

Dellink, R., Chateau, J., Lanzi, E., Magné, B., 2017. Long-term economic growth projections in the shared socioeconomic pathways. Global Environ. Change 42, 200-214.

Dherani, M., Pope, D., Mascarenhas, M., Smith, K.R., Weber, M., et al., 2008. Indoor air pollution from unprocessed solid fuel use and pneumonia risk in children aged under five years: a systematic review and meta-analysis. Bull. World Health Org. 86 (5), 390-398.

Doelman, J.C., Stehfest, E., Tabeau, A., Van Meijl, H., Lassaletta, L., et al., 2018. Exploring SSP land-use dynamics using the IMAGE model: regional and gridded scenarios of land-use change and land-based climate change mitigation. Global Environ. Change 48, 119-135.

Ebi, K., 2014. Health in the new scenarios for climate change research. Int. J. Environ. Res. Public Health 11 (1), 30

Edejer, T., Aikins, M., Black, R., Wolfson, L., Hutubessy, R., et al., 2005. Cost effectiveness analysis of strategies for child health in developing countries. BMJ 331 (1177).

Ezzati, M., Vander Hoorn, S., Lopez, A.D., Danaei, G., Rodgers, A., et al., 2002. Chapter 4: Comparative Quantification of Mortality and Burden of Disease Attributable to Selected Risk Factors. et al. In: Lopez, A.D., Mathers, C.D., Ezzati, M. (Eds.), Global Burden of Disease and Risk Factors. Oxford University Press and The World Bank.

Ezzati, M., Utzinger, J., Cairncross, S., Cohen, A.J., Singer, B.H., 2005. Environmental risks in the developing world: exposure indicators for evaluating interventions, programmes, and policies. J. Epidemiol. Commun. Health 59 (1), 15-22.

FAO, 2008. Methodology for the Measurement of Food Deprivation: Updating the minimum dietary energy requirements. FAO, Rome.

FAO, IFAD, WFP, 2015. The State of food insecurity in the world 2015. Meeting the 2015 international hunger targets: taking stock of uneven progress.

Fishman, S., Caulfield, L.E., de Onis, M., Blossner, M., Mullany, L., et al., 2004. Childhood and maternal underweight. et al. In: Ezzati, M., Lopez, A., Rodgers, A. (Eds.) Comparative Quantification of Health Risks: Global and Regional Burden of Disease due to Selected Major Risk Factors. World Health Organization, Geneva.

Forouzanfar, M.H., Alexander, L., Anderson, H.R., Bachman, V.F., Biryukov, S., et al., 2015. Global, regional, and national comparative risk assessment of 79 behavioural, environmental and occupational, and metabolic risks or clusters of risks in 188 countries, 1990-2013: a systematic analysis for the Global Burden of Disease Study 2013. Lancet 386 (10010), 2287-2323.

Fullman, N., Barber, R.M., Abajobir, A.A., Abate, K.H., Abbafati, C., et al., 2017. Measuring progress and projecting attainment on the basis of past trends of the health-related Sustainable Development Goals in 188 countries: an analysis from the Global Burden of Disease Study 2016. Lancet 390 (10100), 1423-1459.

Hasegawa, T., Fujimori, S., Takahashi, K., Masui, T., 2015. Scenarios for the risk of hunger in the twenty-first century using Shared Socioeconomic Pathways. Environ. Res. Lett. 10 (1), 014010.

Hilderink, H.B.M., Lucas, P.L., ten Hove, A., Kok, M.T.J., de Vos, M.G., et al., 2008. Towards a Global Integrated Sustainability Model: GISMO 1.0 status report. PBL Netherlands Environmental Assessment Agency, The Hague.

Hilderink, H.B.M., Lucas, P.L., Kok, M., 2009. Beyond 2015: Long-term development and the Millennium Development Goals. PBL Netherlands Environmental Assessment Agency, The Hague.

Hill, P.S., Buse, K., Brolan, C.E., Ooms, G., 2014. How can health remain central post2015 in a sustainable development paradigm? Globalization Health 10, 18.

Hughes, B.B., Kuhn, R., Peterson, C.M., Rothman, D.S., Solórzano, J.R., et al., 2011. Projections of global health outcomes from 2005 to 2060 using the International Futures integrated forecasting model. Bull. World Health Org. 89 (7), 478-486.

Hutton, G., Rehfuess, E., Tediosi, F., Weiss, S., 2006. Evaluation of the costs and benefits of household energy and health interventions at global and regional levels. World Health Organization (WHO), Geneva.

Jiang, L., O’Neill, B.C., 2017. Global urbanization projections for the shared socioeconomic pathways. Global Environ. Change 42, 193-199.

KC, S., Lutz, W., 2017. The human core of the shared socioeconomic pathways: population scenarios by age, sex and level of education for all countries to 2100. Global 
Environ. Change 42, 181-192.

Korenromp, E.L., 2005. Malaria Incidence Estimates at Country Level for the Year 2004 . Proposed Estimates and Draft Report. Report World Health Organization, Roll Back Malaria, Geneva.

Kuhn, R., Rothman, D.S., Turner, S., Solórzano, J., Hughes, B.B., 2016. Beyond attributable burden: estimating the avoidable burden of disease associated with household air pollution. PLoS One 11 (3) e0149669.

Lange, S., Klasen, S., 2017. How the new international goal for child mortality is unfair to Sub-Saharan Africa (Again). World Dev. 90, 128-146.

Le Blanc, D., 2015. Towards integration at last? The sustainable development goals as a network of targets. Sust. Dev. 25 (3), 176-187.

Lim, S.S., Allen, K., Bhutta, Z.A., Dandona, L., Forouzanfar, M.H., et al., 2016. Measuring the health-related Sustainable Development Goals in 188 countries: a baseline analysis from the Global Burden of Disease Study 2015. Lancet 388 (10053), 1813-1850.

Liu, L., Oza, S., Hogan, D., Perin, J., Rudan, I., et al., 2015. Global, regional, and national causes of child mortality in 2000-13, with projections to inform post-2015 priorities: an updated systematic analysis. Lancet 385 (9966), 430-440.

Liu, L., Oza, S., Hogan, D., Chu, Y., Perin, J., et al., 2016. Global, regional, and national causes of under-5 mortality in 2000-15: an updated systematic analysis with implications for the Sustainable Development Goals. Lancet 388 (10063), 3027-3035.

Marmot, M., 2010. Fair Society Healthy Lives: the Marmot review. UCL Institute of Health Equity.

Martens, W.J., Niessen, L.W., Rotmans, J., Jetten, T.H., McMichael, A.J., 1995. Potential impact of global climate change on malaria risk. Environ. Health Perspect. 103 (5), 458-464.

Mathers, C.D., Loncar, D., 2006. Projections of global mortality and burden of disease from 2002 to 2030. PLOS Med. 3 (11), 2011-2030.

McMichael, A.J., Campbell-Lendrum, D., Kovats, S., Edwards, S., Wilkinson, P., et al., 2004. Global climate change. et al. In: Ezzati, M., Lopez, A., Rodgers, A. (Eds.), Comparative Quantification of Health Risks: Global and Regional Burden of Disease due to Selected Major Risk Factors. World Health Organization, Geneva.

Morel, C.M., Lauer, J.A., Evans, D.B., 2005. Cost effectiveness analysis of strategies to combat malaria in developing countries. BMJ.

Naghavi, M., Wang, H., Lozano, R., Davis, A., Liang, X., et al., 2015. Global, regional, and national age-sex specific all-cause and cause-specific mortality for 240 causes of death, 1990-2013: A systematic analysis for the Global Burden of Disease Study 2013. Lancet 385 (9963), 117-171.

Niessen, L.W., Hilderink, H.B.M., 1997. The population and health model. In: Rotmans, J., De Vries, B. (Eds.), Perspectives on global change: the TARGETS approach, Cambridge UP.

Niessen, L.W., 2002. Roads to health: multi-state modelling of population health and resource use, Institutes of Public Health and for Medical Technology Assessment. Erasmus University, Rotterdam.

Niessen, L.W., ten Hove, A., Hilderink, H., Weber, M., Mulholland, K., et al., 2009. Comparative impact assessment of child pneumonia interventions. Bull. World Health Org. 87 (6), 472-480.

Niessen, L.W., Mohan, D., Akuoku, J.K., Mirelman, A.J., Ahmed, S., et al., 2018. Tackling socioeconomic inequalities and non-communicable diseases in low-income and middle-income countries under the Sustainable Development agenda. Lancet 391 (10134), 2036-2046.

Nilsson, M., Griggs, D., Visbeck, M., 2016. Map the interactions between Sustainable Development Goals. Nature 534 (7607), 320-322.

O'Neill, B.C., Kriegler, E., Ebi, K.L., Kemp-Benedict, E., Riahi, K., et al., 2017. The roads ahead: Narratives for shared socioeconomic pathways describing world futures in the 21st century. Global Environ. Change 42, 169-180.

Prüss-Ustün, A., Wolf, J., Corvalán, C., Bos, R., Neira, M., 2016. Preventing disease through healthy environments: a global assessment of the burden of disease from environmental risks. World Health Organization.

Prüss-Üstün, A., Kay, D., Fewtrell, L., Bartram, J., et al., 2004. Unsafe water, sanitation and hygiene. In: Ezzati, M., Lopez, A.D., Rodgers, A. (Eds.), Comparative Quantification of Health Risks: Global and Regional Burden of Disease Attributable to Selected Major Risk Factors. World Health Organization (WHO), Geneva.

Prüss-Üstün, A., Bos, R., Gore, F., Bartram, J., 2009. Safer water, better health. Costs, benefits and sustainability of interventions to protect and promote health. World Health Organization, Geneva.

Queenan, K., Garnier, J., Nielsen, L.R., Buttigieg, S., Meneghi, Dd., et al., 2017. Roadmap to a One Health agenda 2030. CAB Rev. 12 (014), 1-17.

Riahi, K., van Vuuren, D.P., Kriegler, E., Edmonds, J., O'Neill, B.C., et al., 2017. The Shared Socioeconomic Pathways and their energy, land use, and greenhouse gas emissions implications: an overview. Global Environ. Change 42 (Supplement C), 153-168.

Sellers, S., Ebi, K., 2018. Climate change and health under the shared socioeconomic pathway framework. Int. J. Environ. Res. Public Health 15 (1), 3.

Smith, L., Haddad, L., 2000. Explaining Child Malnutrition in Developing Countries: A Cross-Country Analysis. International Food Policy Research Institute (IFPRI), Washington D.C.

Stehfest, E., van Vuuren, D.P., Kram, T., Bouwman, L., Alkemade, R., et al., 2014. Integrated Assessment of Global Environmental Change with IMAGE 3.0. Model description and policy applications. PBL Netherlands Environmental Assessment Agency, The Hague.

UN, 2011. World Population Prospects: The 2010 Revision. United Nations, Department of Economic and Social Affairs, Population Division.

UN, 2015. Transforming our world: The 2030 Agenda for Sustainable Development. United Nations, New York.

UN, 2017. World Population Prospects: The 2017 Revision. United Nations, Department of Economic and Social Affairs, Population Division.

Van Ekdom, L., Stenberg, K., Scherpbier, R.W., Niessen, L.W., 2011. Global cost of child survival: estimates from country-level validation. Bull. World Health Org. 89 (4), 267-277.

Van Ruijven, B.J., Levy, M.A., Agrawal, A., Biermann, F., Birkmann, J., et al., 2014. Enhancing the relevance of Shared Socioeconomic pathways for climate change impacts, adaptation and vulnerability research. Clim. Change 122 (3), 481-494.

Van Vuuren, D.P., Lucas, P.L., Hilderink, H., 2007. Downscaling drivers of global environmental change: enabling use of global SRES scenarios at the national and grid levels. Global Environ. Change 17 (1), 114-130.

Van Vuuren, D.P., Kok, M.T.J., Lucas, P.L., Prins, A.G., Alkemade, R., et al., 2015. Pathways to achieve a set of ambitious global sustainability objectives by 2050 . Explorations using the IMAGE integrated assessment model. Technol. Forecast. Social Change 98, 303-323.

Van Vuuren, D.P., Riahi, K., Calvin, K., Dellink, R., Emmerling, J., et al., 2017a. The Shared Socio-economic Pathways: Trajectories for human development and globa environmental change. Global Environ. Change 42 (Supplement C), 148-152.

Van Vuuren, D.P., Stehfest, E., Gernaat, D., Doelman, J.C., Van den Berg, M., et al., 2017b. Energy, land-use and greenhouse gas emissions trajectories under a green growth paradigm. Global Environ. Change 42 (1), 237-250.

Vos, T., Barber, R.M., Bell, B., Bertozzi-Villa, A., Biryukov, S., et al., 2015. Global, regional, and national incidence, prevalence, and years lived with disability for 301 acute and chronic diseases and injuries in 188 countries, 1990-2013: a systematic analysis for the Global Burden of Disease Study 2013. Lancet 386 (9995), 743-800.

Whitmee, S., Haines, A., Beyrer, C., Boltz, F., Capon, A.G., et al., 2015. Safeguarding human health in the Anthropocene epoch: report of The Rockefeller FoundationLancet Commission on planetary health. Lancet 386 (10007), 1973-2028.

WHO, 2002. The World Health Report 2002: Reducing risks, promoting healthy life. World Health Organization, Geneva.

WHO, 2016. Health in the 2030 Agenda for Sustainable Development - Report by the Secretariat. World Health Organization, Geneva.

WHO, 2017a. Inheriting a sustainable world? Atlas on children's health and the environment. World Health Organization, Geneva.

WHO, 2017b. Don't pollute my future! The impact of the environment on children's health. World Health Organization, Geneva.

WHO/UNICEF, 2015. Progress on Drinking Water and Sanitation - 2015 update and MDG assessment. World Health Organization and UNICEF, Geneva.

Wolf, J., Prüss-Ustün, A., Cumming, O., Bartram, J., Bonjour, S., et al., 2014. Systematic review: assessing the impact of drinking water and sanitation on diarrhoeal disease in low- and middle-income settings: systematic review and meta-regression. Trop. Med. Int. Health 19 (8), 928-942.

Woltjer, G.B., Kuiper, M.H., 2014. The MAGNET Model: Module description. LEI Report 14-057. LEI Wageningen UR (University \& Research centre), Wageningen.

You, D., Hug, L., Ejdemyr, S., Idele, P., Hogan, D., et al., 2015. Global, regional, and national levels and trends in under-5 mortality between 1990 and 2015, with scenario-based projections to 2030: a systematic analysis by the UN Inter-agency Group for Child Mortality Estimation. Lancet 386 (10010), 2275-2286. 